Gómez Chávez, Andrés.

Doctorando en Programa de Doctorado en Artes: producción e investigación, Universitat Politècnica de València, Facultad de Bellas Artes, Departamento de escultura, Laboratorio de Creaciones Intermedia LCI.

\title{
Instalación biofílica: Indagaciones plásticas en el uso de la instalación como herramienta para la restauración cognitiva en entornos urbanos precarios
}

\section{Biophilic installation: artistic inquiries for the use of installations as a tool for cognitive restoration in precarious urban environments}

TIPO DE TRABAJO: Comunicación.

PALABRAS CLAVE

Precariedad, Restaurativo, Estrés, Instalación, Urbana, Biofília.

KEY WORDS

Precariousness, Restaurative, Stress, Instalation, Urban, Biophilia.

RESUMEN

La ciudad es la resultante de un entorno diseñado por y para el precariado. El sistema consumista desde la revolución industrial ha contado con tácticas de sometimiento colectivo cuyo alcance ha sido amplificado por la nueva era digital y las nuevas condiciones urbanas han dado paso a la normalización de los casos de trastornos emocionales leves como el estrés y la ansiedad. Producto de la sobresaturación de factores físicos y sensoriales que funcionan a modo de estresores ambientales para los individuos. En un núcleo urbano que no está diseñada para la contemplación, la comunidad se encuentra desprovista de escenarios para la recuperación mental o la introspección individual.

Cabe preguntarnos, ¿Es posible recuperar dinámicas sociales en áreas urbanas mediante experiencias espaciales creadas desde un discurso artístico? La práctica artística se presenta como la oportunidad de generar propuestas de arte público basadas en los patrones del diseño biofílico (Kellert, 2008, 2015) y la Teoría de la Restauración de la Atención TRA (Kaplan; Kaplan, 1989). Estas indagaciones pretenden generar momentos urbanos donde las personas que han estado sometidas a un estado de estrés o fatiga mental, encuentren escenarios que permitan recobrar las funciones cognitivas que han sido reducidas por las demandas del ambiente.

\section{ABSTRACT}

The city is the result of an environment designed by and for the precariat. The consumerist system since the industrial revolution has had collective subjection tactics whose scope has been amplified by the new digital age and the new urban conditions have given way to the normalization of cases of mild emotional disorders such as stress and anxiety. This has resulted in the oversaturation of physical and sensory factors that function as environmental stressors for individuals. In a city that is not designed for contemplation, the community is devoid of scenarios for mental recovery or individual introspection.

We must ask ourselves, is it possible to recover social dynamics in urban ecosystems through spatial experiences created from an artistic discourse? The investigations in the artistic practice is an opportunity to generate public art proposals based on the biophilic design patterns (Kellert, 2008, 2015) and the Attention Restoration Theory ART by Kaplan, Kaplan (1989). The research aims to generate urban moments where people who have been subjected to a state of stress or mental fatigue, find scenarios to recover the cognitive functions that have been reduced by the demands of the environment. 


\section{INTRODUCCIÓN}

El consumismo digital ha transformado el oficio de diseñar, proyectar y construir edificaciones en un producto más al servicio del régimen económico. Esta nueva relación transaccional corresponde a los múltiples proyectos que mediante multimillonarias inversiones públicas buscan replicar el efecto Guggenheim de Bilbao, obras arquitectónicas cada vez más ajenas a las necesidades reales de los habitantes. Los medios internacionales han creado la súper categoría de los Star-Architects, el grupo de afamados diseñadores compuesto por Zaha Hadid, Santiago Calatrava, Frank Gehry, Peter Eisenman, Steven Holl, Norman Foster y Bjarke Ingels. Gobiernos y ayuntamientos les entregan cheques en blanco para garantizar su firma en las diferentes escenografías urbanas que sirvan para ubicar a ciudades genéricas en el competido mapa del turismo urbano cultural. La arquitectura ha perdido su rumbo como ciencia de las humanidades al permitirle a la codicia gubernamental camuflar la precariedad con un nuevo pan y circo arquitectónico.

El paisaje urbano actual está concebido desde esquemas administrativos basados en el funcionalismo y la rentabilidad económica, resultando en la sobresaturación de factores físicos y sensoriales que funcionan a modo de estresores ambientales para los individuos. La psicología ambiental se ha transformado en la herramienta para poder desarrollar correctivos en el diseño urbano. Valera (2019) la define como la disciplina que estudia la relación cognitiva, emocional y conductual de individuos con ambientes físicos.

La urbe es entendida como un sistema vivo producto de la constante relación simbiótica entre el individuo modificador y el ambiente modificado, relaciones reciprocas de conducta - entorno: El individuo proyecta y modifica de acuerdo a sus necesidades el espacio físico, la ciudad asume inicialmente un rol pasivo para lentamente volverse generadora por si misma de nuevas dinámicas sociales que afectan el comportamiento del individuo creador. La restauración psicológica y el contexto ambiental cuentan con décadas de investigación y estudios prácticos tales como las investigaciones de los efectos positivos psicológicos de la naturaleza (Martinez-Soto \& Montero, 2010) y la renovación de recursos funcionales físicos y psíquicos y capacidades cognitivas disminuidas (Hartig \& Staats, 2003).

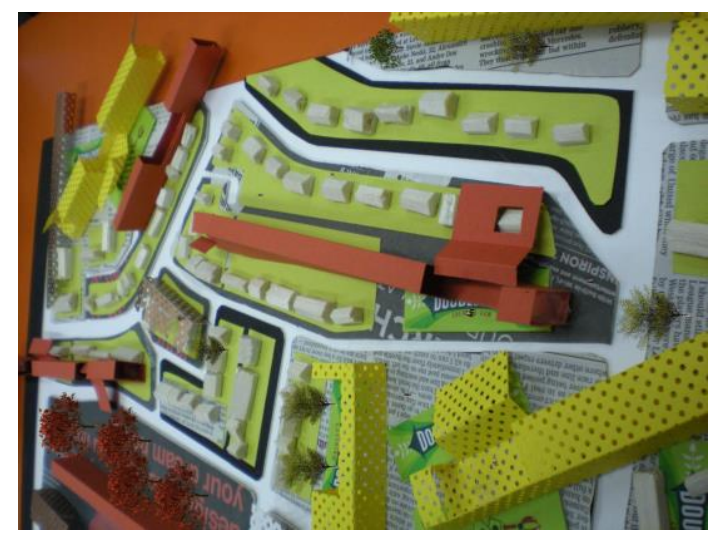

Figura 1. Propuesta de implantación de catalizadores urbanos en zonas residenciales, 2009.

\section{METODOLOGÍA}

El preliminar presentado en las siguientes paginas corresponde a una investigación en desarrollo para el Doctorado en Arte: Producción e Investigación en la Universidad Politécnica de Valencia. El objeto principal de esta naciente investigación es cartografiar, revisar y proponer el empleo de un género de arte público basado en las relaciones de enlace entre la preferencia ambiental y la instalación urbana, ahondando en la correspondencia entre los estímulos biofílicos del entorno físico y las dinámicas generadas en los ciudadanos. Proponiendo una noción de lo efímero a partir del lugar con la intención de ampliar la resonancia del arte fuera del espacio destinado a la exhibición tradicional.

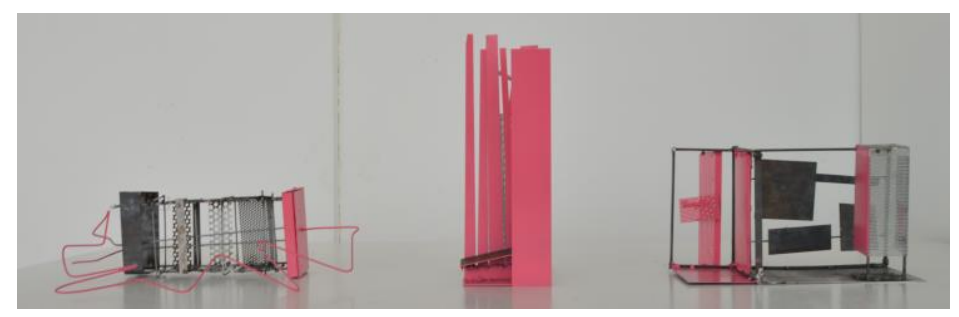

Figura 2. Maquetas de estudio de instalaciones urbanas restaurativas,2017. 
Este proyecto se enmarca en la metodología cualitativa. Los análisis para la obtención de los resultados toman a manera de objeto al lugar (Valencia), como sujeto a una comunidad especifica (por definir) y al artista como mediador social. La innovación se encuentra en un riguroso entendimiento de la literatura disponible para la conceptualización de un discurso filosófico - artístico propio que complemente al proceso arquitectónico (formación profesional del autor). Se busca generar momentos urbanos donde las personas que han estado sometidas a un estado de estrés o fatiga mental, encuentren escenarios que permitan recobrar las funciones cognitivas que han sido reducidas por las demandas del ambiente. Estas intervenciones serán preliminarmente calificadas según la percepción de los usuarios mediante el uso de la Escala de Percepción Restaurativa EPR.

\section{DESARROLLO}

A pesar de ser temáticas actuales producto de las discusiones sobre nuevas economías digitales, la aporofobia y la precariedad son conceptos tan antiguos y urbanos como las ciudades en sí. La diferencia puede radicar en que el individuo contemporáneo vive aislado en un sistema concebido por y para el precariado donde la interacción social que generaba vínculos entre individuos ha sido reemplazada por una modalidad digital del anonimato y se ha dado la normalización de los casos de trastornos emocionales leves, específicamente el estrés y la ansiedad en entornos laborales y/o urbanos. Las problemáticas sociales y estresores ambientales se dan con mayor frecuencia en núcleos urbanos de gran tamaño y estas problemáticas tienden a relacionarse con la recurrencia de desórdenes psiquiátricos (Peen, Schoevers, Beekman \& Dekker, 2010).

Google y Facebook saben que el individuo es más fácil de manejar si está solo, neuronalmente enfermo y necesita del sistema y no de la comunidad para "aconsejarle" qué, cuándo y cómo ser. La sociedad es un colectivo de individuos que debe trabajar para garantizar el acceso inseguro a bienes básico, víctima de la violencia simbólica de un esquema de referentes positivos a los cuales puede "acceder" mediante el consumo de productos y experiencias (Sterling, 2013). La ciudad es precaria porque es la escenografía en la que se mueve el precariado, el ejemplo más palpable de la relación conducta - entorno.

El Institute for Precarious Consciousness (2017) entabla una conexión entre el consumismo y la transformación urbana desde los inicios de la industrialización. La sociedad después de haber experimentado la miseria y el aburrimiento a modo de tácticas de sometimiento por parte del sistema consumista, encuentra en la precariedad el estado mental por excelencia y la ciudad es el escenario perfecto para intensificar sus efectos. La falta de adaptación de las personas a las nuevas y poco sostenibles variables ambientales y los efectos psicofisiológicos producto de la precariedad han derivados en individuos aquejados por vivir en constante estado de alerta por las dinámicas sociales y las condiciones actuales que han rebasado los límites de la adaptación individual (Han, 2013). Si antes se necesitaba de eventos y hechos físicos para satisfacer las necesidades básicas (Maslow, 1943), el urbanita contemporáneo se abastece en la red de la ilusión que genera plenitud digital como tratamiento paliativo a la precariedad física.

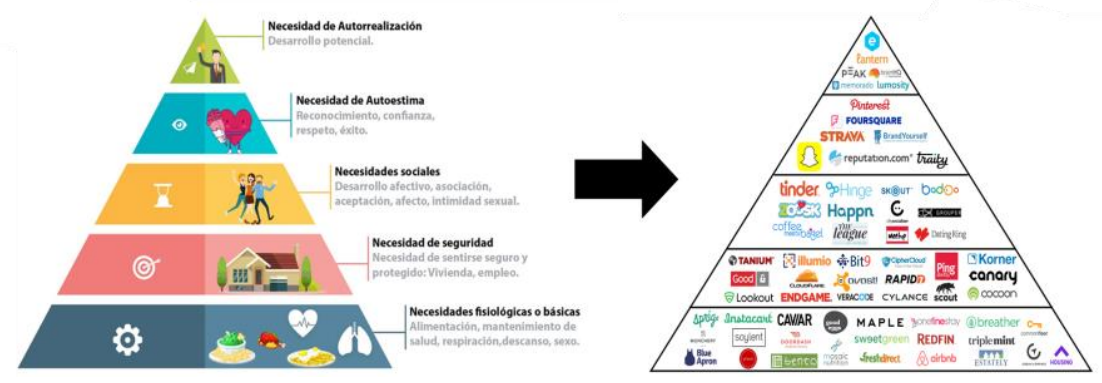

Figura 3. Evolución de la piramide de Maslow, las aplicaciones digitales suplen las necesidades fisicas de los urbanitas. Imágenes extraidas de www.triangulum.com.mx y www.cbinsights.com

\section{La ciudad como hecho cultural}

Las macro modificaciones ecológicas propiciaron el establecimiento de los primeros seres humanos en un conjunto de edificaciones para la creación de una vida en comunidad; la rutina de sus habitantes lentamente se fue haciendo más urbana, menos "salvaje" y más tranquila. Esta nueva relación entre el individuo que habita el entorno construido (adentro) y el entorno natural (afuera) significó el establecimiento de las bases de referencia de las concepciones administrativas, religiosas y artísticas de los primeros urbanitas (Aguelles, 2017).

El carácter urbano, aunque genérico, de las ciudades se debe a dos fundamentos estructurantes: la segregación y la biofobia. La estratificación recae en respuestas desiguales a las necesidades específicas de sectores sociales: entre más baja la clase social, posiblemente mayor precariedad física. El esquema conceptual urbano siempre ha correspondido a la sumatoria de micro territorios definidos por el poder adquisitivo y económico de sus habitantes. La categorización de vecindades es un hecho cultural producto del 
aumento del tamaño de las ciudades: entre más alta la clase social a la que se pertenece, "más" urbano se es. La muralla urbana paso de ser una herramienta defensiva a convertirse en la Edad Media en la barrera simbólica y mental de un rígido sistema socio económico feudal. La fortificación perimetral medieval fue conceptualmente la herramienta de segregación más contundente para delimitar los contrastes entre el adentro y el afuera, el campo y la ciudad, el nativo y el inmigrante, el rico y el pobre (Duby \& Aries \& Rouge, 2001). Tan vigente es aún esta noción que la campaña electoral de extrema derecha MAGA (Make America Great Again) del actual presidente de los Estados Unidos, Donald Trump está basada en el concepto del Muro / Wall.

La biofobia es un constructo popular moderno de las metrópolis en el que deben con un carácter contrario a un entorno natural y demandar un código de pertenencia por parte de sus habitantes, una distinción ante lo que no es urbano. Las ciudades desde los inicios de la civilización encuentran su origen en la domesticación de la naturaleza: estos entornos urbanos son la manifestación física de nuevos límites en el paisaje, ese adentro urbano que difiere del afuera salvaje / rural /campestre (Aguelles, 2017). El oxímoron arquitectónico por excelencia de la "jungla de hormigón" acuñado por Richard Coe para referirse a Nueva York sigue siendo tan válido como lo fue en 1948. Un refrán que denuncia al carácter salvaje del paisaje urbano, un claro ejemplo de la descripción negativa de la ciudad a manera de una selva hostil y peligrosa, sin embargo, una dinámica "normal" asumida en este entorno precario, un colectivo de individuos luchando diariamente para sobrevivir en un ecosistema no natural.

Es por esto que la metrópoli contemporánea está diseñada y acondicionada de manera genérica (Koolhaas, 1997) en cualquier parte del mundo. La ciudad no solo es la macro escenografía del consumismo digital, es en sí misma una experiencia en realidad virtual de la condición. Si los individuos no son conscientes de su participación activa en un sistema corrompido y podrido, difícilmente serán reflexivos sobre el impacto emocional del espacio construido. Es en este momento cuando los artistas y arquitectos pueden manifestarse contra el sistema económico consumista y generar tácticas de resistencia. En este proyecto en particular, se busca hacer de la experiencia espacial urbana, la herramienta fundamental en la re-generación de dinámicas sociales que consoliden nuevamente la trama social y la restauración cognitiva en individuos afectados por estresores urbanos.

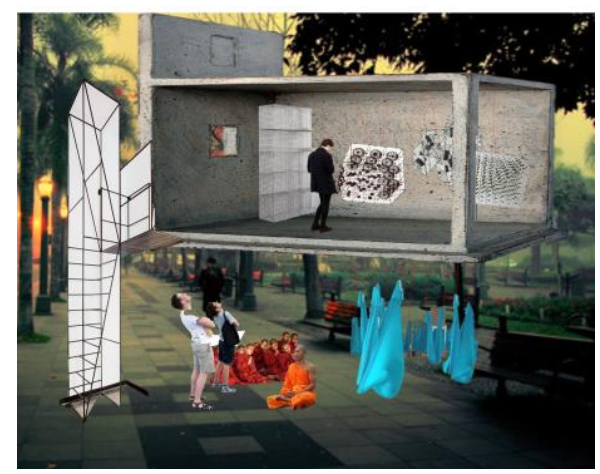

Figura 4. Collage digital de la Instalación urbana MALOKA que reconoce la observación del entorno natural, el descanso y la meditación, 2017.

Es claro que en una ciudad que no está diseñada para la contemplación, la comunidad se encuentra desprovista de escenarios para la recuperación mental o la introspección individual. Los individuos hoy más que nunca necesitan de un refugio en la misma medida en que las ciudades necesitan de un nuevo urbanismo, una mezcla de la propuesta de Sola -Morales (2008) de una acupuntura urbana con la visión de Beatley (2010) de ciudades biofílicas. La propuesta que surge del análisis teórico anterior es la generación de circuitos de instalaciones y acciones urbanas co-creadas, mediante procesos participativos de la ciudadanía, que sirvan de catalizadores urbanos para generan dinámicas sociales sanas y alivianen la carga mental producto del sistema consumista. Un individuo que vive aquejado por los patrones de la precariedad digital posee una capacidad limitada para procesar los estímulos ambientales (que en un escenario natural serian restaurativos), no obstante, en los entornos urbanos los estímulos funcionan a manera de estresores ambientales que amplifican las molestias psicofisiológicas. 


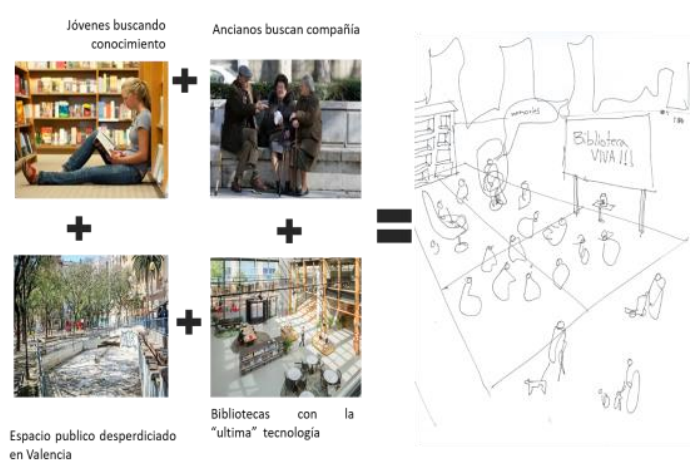

Figura 5. Propuesta de instalación biofílica en Valencia. "Biblioteca viva" que busca la union de diferentes generaciones y la recuperacion del espacio publico para la integración nuevamente de la trama social, 2018.

\section{La preferencia ambiental como herramienta social}

El estrés es una reacción fisiológica que en su conjunto preparan al organismo para la acción y generan la respuesta necesaria para la supervivencia. Cuando esta respuesta natural se da de manera constante y excesiva pierde su justificación ecológica y genera la sobrecarga mental del individuo. El estrés ambiental puede genera síntomas de malestar y ansiedad, alteraciones en los vínculos sociales, déficit comportamental, desviación de la atención y falta de concentración (OMS,2004).

Los posibles detonantes de esta molestia neuronal pueden ser de cinco tipos. (Evan \& Cohen,1987. Burton, 1990. Van den Berg, 2007. Van Dorst, 2005. Montgomery, 2014. la plataforma digital Zipjet, 2017 y Koene,2018).

1. Estresores por la propia condición urbana como el ruido, la mala calidad del aire y la contaminación lumínica.

2. Estresores por el ambiente urbano como el agobio por el aumento en el número de personas, paisajes aburridos, basura y grafiti, trafico, accesibilidad a entornos verdes, transporte público y la falta de escala de las nuevas edificaciones

3. Estresores sociales como la desigualdad de género, preferencia sexual y raza, falta de redes de apoyo social, percepción de seguridad y crimen.

4. Estresores relacionados a la salud como la salud mental, la dieta, la falta de ejercicio, obesidad, exposición a gérmenes, virus y agentes patógenos.

5. Estresores económicos como el desempleo, la deuda, seguridad social y el poder adquisitivo de la familia.

La preferencia ambiental es la herramienta propuesta en esta investigación para combatir el estrés urbano. Dentro de los múltiples modelos teóricos de la preferencia ambiental, se ha decidido utilizar el Modelo Informacional de Preferencia Ambiental (1982) y la Teoría de la Restauración de la Atención ART (1989) por su importancia como fuente bibliográfica de todos los trabajos actuales, por contar con mayor reconocimiento académico y brindar la mayor posibilidad de reinterpretación mediante la práctica artística.

Estos dos modelos complementarios y conceptualizados por Stephen y Rachel Kaplan, tienen un enfoque evolucionista que proponen a la preferencia ambiental como restaurador cognitivo y psicofisiológico debido a una respuesta innata del ser humano mediante la interacción inmediata o inferida con el entorno natural. Un ambiente restaurador es aquel que renueva los recursos atencionales de los individuos debido a que cuenta con características ambientales restaurativas, fomenta la reflexión, restaura los recursos agotados de tipo emocional y funcional, contribuyen a la reducción del stress y a la recuperación de la fatiga mental (Kaplan, 1995; Ulrich et al., 1991). Para la correcta restauración cognitiva, se debe garantizar que la percepción e interacción en las instalaciones biofílicas cumpla con propiedades restaurativas del Modelo de Preferencia Ambiental: Coherencia, legibilidad, complejidad y misterio. De la misma manera con las dimensiones de la Restauración de la Atención: Fascinación, escape o evasión de la rutina (being away), extensión y compatibilidad. 


\begin{tabular}{|c|c|c|}
\hline COMPRENSIÓN & EXPLORACIÓN \\
\hline $\begin{array}{c}\text { SECUENCIA INMEDIATA } \\
\text { Plano inmediato de visión }\end{array}$ & $\begin{array}{l}\text { Caracteristicas del ambiente están } \\
\text { relacionadas entre si generando un } \\
\text { todo coherente que puede } \\
\text { organizarse fácilmente. }\end{array}$ & $\begin{array}{c}\text { 3. COMPLEIDAD } \\
\text { Es la riqueza informativa de la } \\
\text { escena. Lo que equilibra el interés } \\
\text { que el individuo tiene en } \\
\text { adentrarse en el ambiente. }\end{array}$ \\
\hline $\begin{array}{c}\text { SECUENCIA IMMERSIVA } \\
\text { La tercera dimensión del } \\
\text { paisaje }\end{array}$ & $\begin{array}{l}\text { 2. LEGIBILIDAD } \\
\text { Lectura perceptual fácil y correcta } \\
\text { del ambiente. La "Coherencia } \\
\text { esperada" del paisaje que hace } \\
\text { posible en el futuro la ubicación y el } \\
\text { recorrido. }\end{array}$ & $\begin{array}{l}\text { 4. MISTERIO } \\
\text { La promesa de más información al } \\
\text { incorporarse en el ambiente. Es la }\end{array}$ \\
\hline
\end{tabular}

Figura 6. Matriz de recopilación de multiples autores sobre el Modelo Informacional de Preferencia Ambiental.

\begin{tabular}{|c|c|c|}
\hline & COMPRENSIÓN & ABSTRACCIÓN \\
\hline $\begin{array}{l}\text { SECUENCIA INMEDIATA } \\
\text { Plano inmediato de visión }\end{array}$ & $\begin{array}{l}\text { 1. FASCINACIÓN } \\
\text { Atención involuntaria. Estímulos que } \\
\text { no buscan dominar la atención o } \\
\text { perturbar, son percibidos pero no } \\
\text { requirieren esfuerzos ni atención } \\
\text { directa. }\end{array}$ & $\begin{array}{l}\text { 2. ESCAPE } \\
\text { Alejamiento psicológico que permite } \\
\text { hacer un intercambio de contenido } \\
\text { cognitivo distinto al experimentado } \\
\text { cotidianamente. }\end{array}$ \\
\hline $\begin{array}{l}\text { SECUENCIA IMMERSIVA } \\
\text { La tercera dimensión del } \\
\text { paisaje }\end{array}$ & $\begin{array}{l}\text { 4. COMPATIBILIDAD } \\
\text { La percepción de que el ambiente } \\
\text { se adapta a los propósitos del } \\
\text { visitante. El grado en que el } \\
\text { ambiente coincide y apoya las } \\
\text { metas e inclinaciones personales }\end{array}$ & $\begin{array}{l}\text { 3. EXTENSIÓN } \\
\text { Genera la percepción de estar " en } \\
\text { un mundo aparte", inmersión } \\
\text { mental en otro mundo producto de } \\
\text { encontrar coherencia y sentido en } \\
\text { el ambiente evaluado. }\end{array}$ \\
\hline
\end{tabular}

Figura 7. Matriz de recopilación de multiples autores sobre las dimensiones de la Restauración de la Atención.

\section{La Biofília como lenguaje artístico}

Aunque Erich Fromm en 1973 es el primer autor en analizar la relación innata humano-naturaleza. Edward O. Wilson es quien en su obra Biophilia (1984) logra generar un reconocimiento mediático y popularizar la hipótesis de la biofilia. Término empleado para referirse a la necesidad genética e inconsciente de todos los seres humanos con los paisajes naturales, debido al poder terapéutico en esta transacción reciproca de conducta - entorno. Cualquier urbanita precario encuentra en un viaje a la playa o a la montaña la manera más eficiente de resetear su cerebro y lograr la recuperación de cualquier síntoma del estrés laboral.

La aplicación de la biofília en el diseño es conocida como diseño biofílico y Stephen R. Kellert es la figura académica más representativa, sus trabajos se remontan a 1997 con la publicación del "rango de valores biofílicos". En 2008 publica "Dimensiones, elementos y atributos del diseño biofílico" junto a Judith H. Heerwagen y Martin L. Mador, en este texto determinan seis categorías de diseño (características ambientales, formas y figuras naturales, procesos y patrones naturales, luz y espacio, relación con base en el lugar y relaciones humano-naturaleza evolucionadas) y los respectivos setenta atributos aplicables en el diseño. En 2015 , probablemente producto del éxito de los "14 patrones de diseño biofílico" de Terrapin Bright Green (2014), Kellert junto a Elizabeth F. Calabrese publican "Principios, experiencias y atributos del diseño biofílico" en el que reducen el listado a tres categorías de diseño y veinticuatro atributos aplicables.

\begin{tabular}{|c|c|c|}
\hline $\begin{array}{l}\text { Experiencia directa } \\
\text { con naturaleza }\end{array}$ & $\begin{array}{l}\text { Experiencia indirecta con } \\
\text { la naturaleza }\end{array}$ & $\begin{array}{l}\text { Experiencias de } \\
\text { Iugar y espacio }\end{array}$ \\
\hline $\begin{array}{ll}\text { - } & \text { Luz } \\
& \text { Aire } \\
\text { - } & \text { Agua } \\
\text { - } & \text { Plantas } \\
\text { - } & \text { Animales } \\
\text { - Clima } \\
\text { - } & \text { Paisajes naturales y } \\
\text { ecosistemas } \\
\text { - } & \text { Fuego }\end{array}$ & $\begin{array}{l}\text { - Imágenes de naturaleza } \\
\text { - } \text { Materiales naturales } \\
\text { - } \text { Solores naturales } \\
\text { - Fulación de aire y luz natural } \\
\text { - Evocación de naturaleza } \\
\text { - Riqueza de la información } \\
\text { - Edad, cambio y patina de tiempo } \\
\text { - Geometrías naturales } \\
\text { - Biomimética }\end{array}$ & $\begin{array}{l}\text { - Perspectiva y refugio } \\
\text { - } \text { Complejidad } \\
\text { organizada } \\
\text { - Integración de las } \\
\text { partes en el todo } \\
\text { - Espacios de transición } \\
\text { - } \text { Movilidad y wayfinding } \\
\text { - Apego ecológico y } \\
\text { cultural al lugar }\end{array}$ \\
\hline
\end{tabular}

Figura 8. Patrones de la biofilia. "Principios, experiencias y atributos del diseño biofílico" Kellert y Calabrese, 2015. 
Aunque la palabra biofília es nueva en el entorno castellano y aun no es reconocida por la RAE, el discurso biofílico es un importante boom de marketing a nivel mundial. La sede principal de Amazon en Seattle (USA) o la recién inaugurada tienda de Apple en Macao (China) son nuevas edificaciones que pregonan estar desarrolladas desde un enfoque social para lograr el bienestar mental de los usuarios, la nueva determinante que prima por encima del competido mercado arquitectónico de la sostenibilidad y los edificios de bajo consumo energético. Las piezas instalativas urbanas que actualmente siguen el discurso restaurativo caen en el error de ser soluciones estéticas y elitistas para contrarrestar los efectos en el joven y afectado millenial newyorkino o londinense. "Hudson Yards" (2019) de Thomas Heatherwick acaba de ser inaugurada como un hito paisajístico inmersivo en la Gran Manzana, correspondiendo únicamente a un nuevo impulso en una zona altamente apetecida por proyectos inmobiliarios en el parque lineal High Line. "Paradise now" (2018), fue ubicada en una exclusiva plaza en Londres y creada por el estudio de diseño Bompas \& Parr para ostentar el título de primer spa urbano y experiencia multisensorial que ofrecía a su exclusiva clientela / visitantes terapias para la restauración mental.

\section{CONCLUSIONES}

El intercambio para suplir necesidades es una realidad histórica del ser humano, sin embargo, las afectaciones en la sociedad contemporánea son relativas a la transformación digital que se inició hace aproximadamente tres décadas. El esquema consumista actual es la versión refinada y digital de un proceso que se inició con la revolución industrial y acarreó las mayores trasformaciones en el entorno urbano. Las transformaciones en las dinámicas sociales y la revolución tecnología digital van a una velocidad imposible de asumir por las medidas correctivas de las administraciones públicas y las intervenciones biofilicas pueden presentarse a manera de respuesta a esta necesidad mundial. La globalización digital está creando sujetos que no tienen claras las nociones del adentro y el afuera, carecen de herramientas para su autoconstrucción interior y buscan respuestas en el consumo desmedido de productos (Bauman, 2007).

El reto plástico está en la construcción de una propuesta de tipología intalativa urbana creada desde la correspondencia entre los estímulos biofílicos del entorno físico y la responsabilidad social. El desafío moral está en no caer en la búsqueda de indagaciones formales que nieguen la capacidad de la instalación como catalizador de las nuevas dinámicas simbólicas que se pueden generar en los ciudadanos. Estas propiedades corresponden a juicios inconscientes sobre características estructurantes de los paisajes y se encuentran relacionadas a atributos de forma y composición en estos Staats (2012). Para que el efecto restaurativo genere el arousal optimo, Staats propone evitar caer en una estrategia de conducta exploratoria específica, donde los individuos se enfrentan con un estímulo nuevo y complejo. Su recomendación es usar una exploración diversiva para mantener el nivel de estimulación en un nivel óptimo, para lo cual se debe originar en el usuario las motivaciones básicas de comprensión y exploración en una secuencia preliminar (plano inmediato de visión) a una secuencia inmersiva (la tercera dimensión del paisaje). El beneficiario tiene contacto visual con el paisaje y/o instalación biofílica, para lo cual debe ser comprensible, cumpliendo con las cualidades de coherente y legible. El éxito en esta primera etapa genera una segunda motivación inferida de exploración, en cuyo caso debe cumplir con las propiedades de complejidad y misterio. Las instalaciones biofílicas deben forjar una relación simbólica entre los usuarios y los entornos intervenidos. Búsquedas plásticas que se alejen del concepto básico que la "conexión con la naturaleza" puede inmediatamente representar en el imaginario colectivo: la incorporación de plantas y componentes orgánicos debido a la asociación directa en la preferencia ambiental. Para cumplir con el objetivo principal planteado, la práctica artística debe lograr el entendimiento y la significación formal de las ocho cualidades restaurativas de una manera contundente en la comunidad específica a intervenir. Si las obras creadas son sobre-diseñadas resultarían en el efecto contrario a la restauración, puesto que si son estructuras que sobre demandan la atención del usuario se convierten en nuevos estresores ambientales.

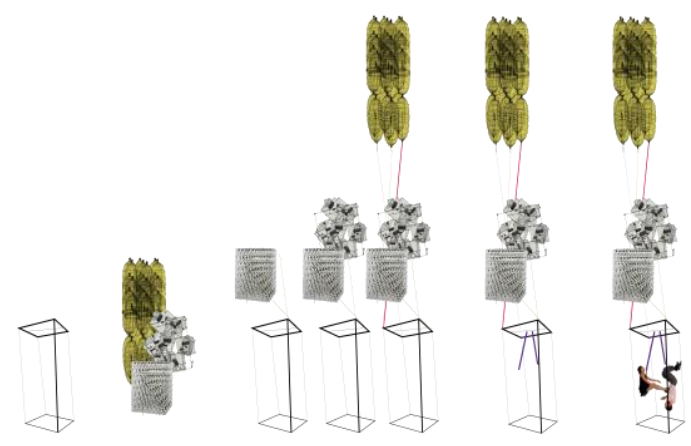

Figura 9. Maqueta virtual de la propuesta de Instalación urbana UKA que permite el ejercicio físico, yoga aéreo y estiramiento en entornos urbanos, (2017.

Estas acciones se deben entender como un nuevo refugio comunitario, un espacio simbólicamente solido que permita la pausa, la introspección y la recarga cognitiva de la población intervenida. Para lograr estas aspiraciones es fundamental entender el papel de la co- creación y la participación comunitaria y así lograr mejores indicadores de restauración simbólica. Descender del campo abstracto las ocho cualidades restaurativas es únicamente posible con la participación comunitaria, la co-creación es la clave del éxito al permitir 
controlar de manera más efectiva las variables en los resultados finales debido a la relatividad entre las cualidades objetivas del estímulo ambiental y los efectos sobre las personas, puesto que el nivel de afectación, percepción y recuperación depende de las actitudes ambientales de cada individuo.

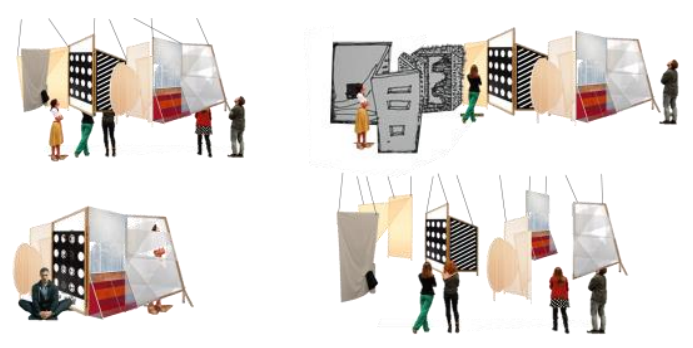

Figura 10. Collage digital de posibles módulos prefabricados que permiten múltiples configuraciones en diferentes instalaciones urbanas, 2018.

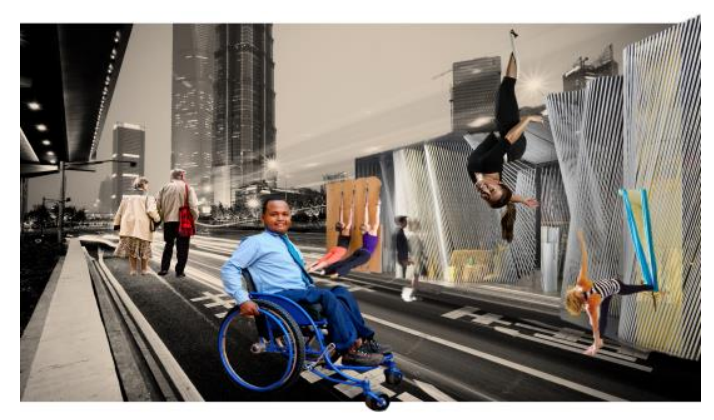

Figura 11. Collage digital de la Instalación urbana NET-A que promueve el ejercicio físico y la terapia deportiva asistida, 2018.

\section{FUENTES REFERENCIALES}

Agulles, J. (2017). La destrucción de la ciudad. El mundo urbano en la culminación de los tiempos modernos. Madrid: Los libros de la catarata.

Bauman, Z. (2000). Modernidad líquida. Buenos Aires: Fondo de cultura económica.

Bauman, Z. (2007). Vida de consumo. Buenos Aires: Fondo de cultura económica.

Burton, I. (1990). Factors in urban stress. The Journal of Sociology \& Social Welfare, 17(1), Article 5.

Caporal, L. y Flores L.M. (2015). Adaptación de la escala de percepción de restauración ambiental en parques. Investigación y practica en psicología del desarrollo, (1), 245-251.

Desmet, P.M.A. y Pohlmeyer, A.E. (2013). Positive design: An introduction to design for subjective well-being. International Journal of design, 7(3), 5-19.

Duby, G., Aries, P., y Rouge, M. (2001). La alta edad media occidental / Historia de la vida privada. Del imperio Romano al año mil. España: Editorial Tauruas.

Gehl, J. (2013). La humanización del espacio urbano: la vida social entre los edificios. Barcelona: Editorial Reverté.

Han, B. (2013). La sociedad de la transparencia. España: Herder.

Irepan M. y Salvador-Ginez, O. (2016). Validación psicométrica de la escala de restauración ambiental percibida en escenarios universitarios. Revista Latinoamericana de Medicina Conductual, 6(1), 33-40.

Kaplan, R. y Kaplan, S. (1989). The experiencia of nature: a psychological perspective. New York: Cambridge University Press. 
Koene, M. (2018). Urban stress: Research into the reduction of urban stress through urban design (Master thesis no publicado). Delft University of Technology, Netherlands.

Koolhaas, R. (2006). La ciudad genérica 1997 (1a ed.). Barcelona: Editorial Gustavo Gili.

Martinez-Soto, J., Montero-López, M. y Chiapas, J.M.R. (2016). Efectos Psicoambientales de las áreas verdes en la salud mental. Revista Interamericana de Psicología / Interamerican Journal of Psychology (IJP), 50(2), 204-214.

Martinez-Soto, J., Montero-López, M. y Cordova-Vazquez, A. (2014). Restauración psicológica y naturaleza urbana: algunas implicaciones para la salud mental. Salud Mental, 37(2), 217-224.

Mejia, A. J. y Lagunes, R. (2015). Restauración psicológica en la escuela: el papel del entorno físico en la naturaleza. Pampedia, 11(Julio 2014 - junio 2015), 62-72.

Press. M, Cooper, R. (2007). El diseño como experiencia, el papel del diseño y los diseñadores en el siglo XXI. Barcelona: Editorial Gustavo Gili.

Santalla-Banderali, Z. (2016). Capacidad restauradora percibida de los ambientes y funcionamiento atencional. Boletín de la escuela de Psicologia UCAB, 51-67

Sieverts, T. (2003). Cities without cities. An interpretation of the Zwischenstadt. Abingdon: Spon Press.

Staats, H.J. (2012). Perspectivas en la investigación sobre preferencia ambiental: tiempo, categorías y realidad. Apuntes de Psicología. Número especial: 30 años de apuntes de Psicología, 30 (1-3), 119-130.

Valera, S. (2019). Elementos básicos de psicología ambiental. Universitat de Barcelona. Consultado el 8 de febrero de 2019 de: www.ub.edu/psicologia ambiental/psicologia ambiental

Van den Berg, A., Harting, T. y Staats, H.J. (2007). Preferences for nature in urbanized societies: Stress, restoration, and the pursuit of Sustainability. Journal of Social Issues, 63(1), 79-96. 